\title{
The Interaction Effect of Perceived Competence and Goal Harmony on Perceived Usefulness
}

\author{
Tove Bøe \\ School of Business and Social Science, University College of Southeast Norway, Ringerike, Norway \\ Email: tove.boe@hit.no
}

Received 29 April 2016; accepted 31 May 2016; published 3 June 2016

Copyright () 2016 by author and Scientific Research Publishing Inc.

This work is licensed under the Creative Commons Attribution International License (CC BY).

http://creativecommons.org/licenses/by/4.0/

(c) (i) Open Access

\begin{abstract}
The aim of this study is to examine the factors that influence teachers' perceived usefulness of e-learning technology in a university context. We argue that perceived competence and goal harmony will have an interaction effect on perceived usefulness as well as being predictor variables themselves. Additionally, we include and test the established constructs of confirmation of preadoption expectations, and perceived ease of use as independent variables and controls in the study. The model is tested in a university setting, and the results show that perceived competence and goal harmony are positively related to perceived usefulness. The negative interaction effect between goal harmony and perceived competence on perceived usefulness is also supported, indicating the synergic effect of these two constructs on the dependent variable.
\end{abstract}

\section{Keywords}

Perceived Usefulness, Perceived Competence, Goal Harmony

\section{Introduction}

The use of e-learning technology in higher education is increasing, and the education landscape is exposed to major changes. E-learning initiatives are expected to increase flexibility for students, expand enrolment, enhance the reputation of institutions, and, increase students' learning outcomes (Islam, 2012b). Although the students seem to be motivated and ready, this is not always the case for the teaching staff (Ørnes, 2015). The educational institutions must support and educate their faculty staff to ensure that they are prepared for the changes they will meet. The teachers are and will be the key when it comes to effective use of technology in teaching, learning, and assessment. Thus, the focus for the university management will be to ensure that the faculties are adequately 
prepared and able to use and experience the usefulness of the wide range of tools available.

Implementation of information and communication technology has been regarded as one of the dominant predictors of organizational performance and the expectation of increased organizational performance has reached the institutions of higher education. Acceptance and continued use of e-learning technology has received considerable attention from information system (IS) researchers. Perceived usefulness is a central construct in the two dominant theories of technology acceptance and continued use, i.e. Technology Acceptance Model (TAM) (Davis, 1989), and Information Systems Continuance Theory (ISCT) (Bhattacherjee, 2001). Both theories rely on the strong role of users' perceived usefulness when explaining the users' decision of acceptance and continued use of a technology. In fact, perceived usefulness is probably regarded as the most important antecedent of IS continuance intention because: "[...] it is the only belief that is demonstrated to consistently influence user intention across temporal stages of IT use” (Bhattacherjee, 2001: p. 355). Thus, the users' perceived usefulness of a system is documented to be among the most important prerequisite for acceptance and continued use (Laugesen, 2012).

Given the pervasive role of perceived usefulness in acceptance and intention of continued use of IS (Hong, Thong, \& Tam, 2006), this study reviews and examines the impact of the antecedents on perceived usefulness. TAM predicts that the main antecedent of perceived usefulness is perceived ease of use (Davis, 1989). ISCT predicts that the antecedent of perceived usefulness is confirmation of the pre-accepted expectations (Bhattacherjee, 2001). Additionally, a few studies have extended these basic models and have included constructs such as perceived competence (Sørebø, Halvari, Gulli, \& Kristiansen, 2009; Teo, Lee, Chai, \& Choy, 2009) from Self-Determination Theory (SDT) and goal harmony (Bøe, Gulbrandsen, \& Sørebø, 2015) from Principal-Agent Theory (PAT). Based on a review of previous studies, we propose a research model including the antecedent of perceived competence, goal harmony, perceived ease of use, and confirmation of pre-adoption expectations, between university management and teachers. Particularly, we examine the potential interaction effect of perceived competence and goal harmony, and hypothesize a negative synergic effect on perceived usefulness. Thus, the study uses perceived usefulness as the dependent variable, and perceived competence, goal harmony, perceived ease of use, and confirmation, as independent variables. The latter two constructs have shown great impact on the dependent variable, and are included as control variables.

This study makes two contributions to the higher education e-learning literature. First, we address the direct effect of goal harmony and perceived competence on perceived usefulness. The importance of including other alternative theoretical perspectives in connection with the established models of TAM and ISCT has been asked for in the literature (Bhattacjerjee \& Lin, 2014). Studies of IS implementation show that IS-users can be motivated by harmonizing the goals of management and users (Bhattacherjee, 1998) and that utilizing e-learning technology requires a certain initial level of confidence in using e-learning technology (Teo, Lee, Chai, \& Choy, 2009). Although a few studies have tested either the effect of perceived competence (Sørebø, Halvari, Gulli, \& Kristiansen, 2009) or the effect of goal harmony (Bøe, Gulbrandsen, \& Sørebø, 2015) on perceived usefulness, no previous studies have integrated both of these two construct in tandem as antecedents of perceived usefulness. Second, we establish the argument that perceived competence and goal harmony will have an interaction effect on perceived usefulness. In the case of two quasi moderators, one cannot interpret which of the variables moderates the other: "[...] the moderator effect [i.e., quasi moderator] is unclear because each of the independent variables can, in turn, be interpreted as a moderator” (Sharma, Durand, \& Gur-Arie, 1981: p. 294). We argue that the higher the perceived competence, the lower the effect of goal harmony on perceived usefulness; and, the stronger the goal harmony between management and users, the lower the effect of perceived competence on perceived usefulness. Accordingly, the second contribution is the conceptual development and empirical test of this contingent effect on perceived usefulness.

The paper proceeds as follows: Section 2 presents the theory and hypotheses, Section 3 describes the methods used, and Section 4 presents the data analyses and empirical results. The final Section 5 contains a discussion of our research findings, and includes suggestions for future research and implications for theory and practice.

\section{Theory and Hypotheses}

In Section 2.1, we outline the study's dependent variable, review the literature on determinants of perceived usefulness, and present the study's research model. In the subsequent sections, the identified antecedents of perceived usefulness and the belonging hypotheses are presented. 


\subsection{Perceived Usefulness: The Construct and Its Determinants}

Perceived usefulness has its origin in technology acceptance model (TAM) (Davis, 1989). Davis (1989) defined perceived usefulness as the degree to which a person believes that using a particular system (technology) would enhance his or her job performance. According to TAM, technology acceptance is predicted by perceived usefulness and perceived ease of use and perceived usefulness is predicted by perceived ease of use. Information systems continuance theory (ISCT) was developed by Bhattacherjee (2001), partly based on TAM and expectation confirmation theory (ECT), and has turned out to be the dominant theory in explaining users' continued use of information technology (IT) (Laugesen, 2012). This theory proposes that user intentions of continued use of IS are determined by the level of confirmation of their pre-acceptance expectations, the post-acceptance perceived usefulness of the system, and the perceived level of satisfaction, and that perceived usefulness is predicted by the level of confirmation. Perceived usefulness has been shown to be among the strongest predictor of continued use (Laugesen, 2012; Bhattacherjee, 2001). The dominating position of perceived usefulness in an e-learning context from a teacher perspective is supported by several studies (Hung, Chang, \& Hwang, 2011; Sørebø, Halvari, Gulli, \& Kristiansen, 2009; Islam, 2011; Islam, 2012a; Tao, Cheng, \& Sun, 2012). Given this strong position of perceived usefulness, in acceptance as well as in continued use, the goal for this study is to review and test its' most dominating predictors.

Bhattacherjee \& Lin (2014) focus on the importance of considering inclusion of other alternative theoretical perspectives in connection with the established models. Consequently, several studies have extended TAM and ISCT with inclusion of other theories and antecedents. In a study by Teo et al. (2009), an evaluation of the factors that influence teachers' perceived usefulness was performed, and they received support for the direct effect of perceived competence. Sørebø et al. (2009) integrate ISCT with self-determination theory (SDT) and evaluate the significance of perceived autonomy, perceived competence, and perceived relatedness as predictors of perceived usefulness. Only the antecedent of perceived competence was empirically supported. Principal-agent theory (PAT) has been widely used to describe relationships in organizations (Eisenhardt, 1989), and in a study by Bøe et al. (2015), the construct of goal harmony received empirical support as a predictor of perceived usefulness.

Based on the discussion above, we propose a research model (Figure 1) with perceived usefulness as the dependent variable, and with perceived competence (SDT), goal harmony (PAT) as independent variables. Our model includes an interaction effect of perceived competence and goal harmony on the dependent variable. We argue that perceived competence and goal harmony will to a certain degree act as substitutes and together have a negative synergic effect on perceived usefulness. Additionally, we include the established antecedents of confirmation (ISCT) and perceived ease of use (TAM) as additional control variables in our study.

\subsection{Perceived Competence}

Perceived competence can be defined as the users potential to fully utilize information and communication

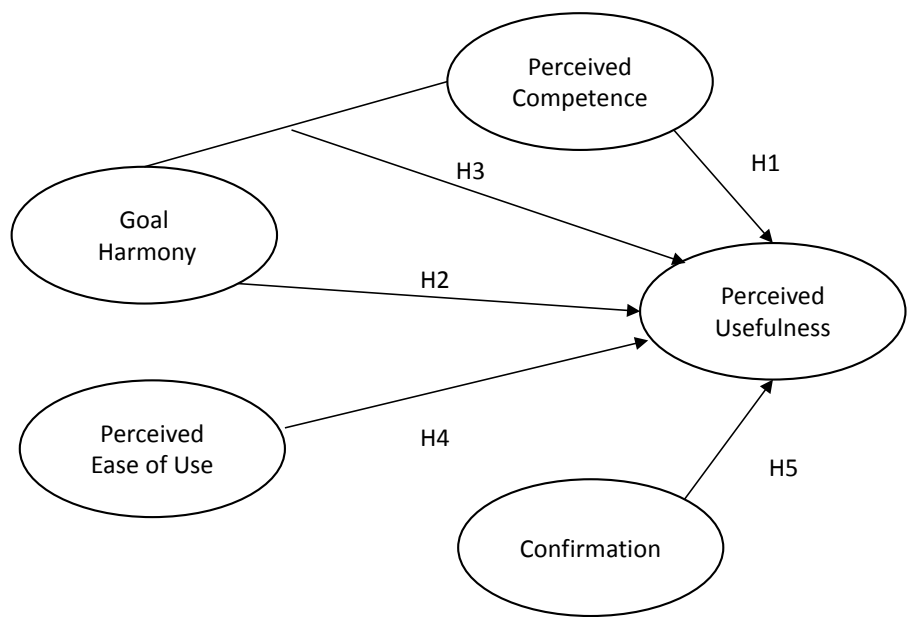

Figure 1. Research model. 
technology in order to improve his or her performance of specific job tasks (Lam \& Lee, 2006), and refers to the desire to feel effective in attaining valued outcomes. The concept originates in self-determination theory (SDT), where intrinsic and extrinsic motivation is the core elements. Intrinsic motivation refers to doing an activity out of genuine interest, while extrinsic motivation refers to doing an activity for an external reason outside the activity. The theory proposes that the adoption of intrinsic motivation over extrinsic motivation depends on the satisfaction of three basic psychological needs for perceived autonomy, perceived competence, and perceived relatedness (Roca \& Gagné, 2008).

Utilizing e-learning technology requires a certain level of digital competence. Perceived competence measures the level of confidence in using e-learning technology (Teo, Lee, Chai, \& Choy, 2009). Teachers need this competence in order to take full advantage of these tools and to facilitate the best possible learning situation for their students. Fleming et al. (2007) state that once teachers acquired a certain level of competence, they will evaluate the systems as useful and are more likely to integrate the technology in their future teaching. Previous studies (Sørebø, Halvari, Gulli, \& Kristiansen, 2009; Teo, Lee, Chai, \& Choy, 2009) support the relationship between perceived competence and perceived usefulness. We propose:

H1: Teachers' perceived level of competence has a positive effect on their level of perceived usefulness.

\subsection{Goal Harmony}

Organizational goals can be defined either by management or in a participative process involving the employees. Universities invest in e-learning technology to obtain flexibility and improve learning outcomes for the students, and management expects teachers to use this technology to reach the defined goals. Utilizing the principal-agency management perspective (Wright, Mukherji, \& Kroll, 2001), we argue below why and how the degree of goal harmony affects users' perceived usefulness of IS. Based on explicit assumptions about the behavior of agents, PAT attributes the agency problems to three factors (Bhattacherjee, 1998): 1) goal conflict: the agent and the principal may have different goals; 2) information asymmetry: the agent cannot be observed by the principal; and 3) differential risk preferences. PAT has been criticized because its assumptions discount situations that better reflect therealities of real-life principal-agency relationships (Eisenhardt, 1989; Perrow, 1986; Wright, Mukherji, \& Kroll, 2001). Following Eisenhardt (1989) and Wright et al. (2001), however, we relax the PAT assumption of a state of universal goal conflict by introducing this assumption as a variable in the research model. We frame the variable as goal harmony, and defines it as the degree to which teachers (agents) support the goals defined by management (principal).

If there is low goal harmony in management-teacher relationships, the teacher may act opportunistically since the management cannot fully monitor the teacher's behavior and enforce compliance (Eisenhardt, 1989). However, as goal harmony increases, there is a decreasing need for both incentive measures and monitoring arrangements (Wright, Mukherji, \& Kroll, 2001), and research on IS implementation documents that users can be motivated to utilize IT appropriately by harmonizing the goals of management and users (Bhattacherjee, 1998). Thus, one should expect that teachers having common goals with management will evaluate the systems as useful and thereby affect the rational component of users' perceived usefulness (Bøe, Gulbrandsen, \& Sørebø, 2015), and be more likely to integrate e-learning technology in their work. Thus, the following hypothesis is proposed:

H2: Teachers' perceived level of goal harmony with management has a positive effect on their level of perceived usefulness.

\subsection{Interaction Effect of Goal Harmony and Perceived Competence}

In this study, we hypothesize that perceived competence and goal harmony will have an interaction effect on perceived usefulness as well as being predictor variables themselves. First, we address the argument that increasing levels of perceived competence will negatively moderate the effect of goal harmony on perceived usefulness. Second, it is argued that increasing levels of goal harmony will negatively moderate the effect of perceived competence on perceived usefulness. Finally, we argue that these to quasi moderators (Sharma, Durand, \& Gur-Arie, 1981: p. 294), goal harmony and perceived competence, will have a negative interaction effect on perceived usefulness.

Goal harmony as (quasi) moderator. As discussed above, the PAT assumption of universal goal conflict between management and users fails to consider the very real variance in goal harmony that can and does exist 
across user-management relationships (Eisenhardt, 1989; Wright, Mukherji, \& Kroll, 2001). Thus, IS empirical models should integrate goal harmony, as this construct may be a cost-effective instrument to reduce the need for high user competence in order to accomplish perceived usefulness. In goal-harmony situations, the agency proposal that teachers will invariably use their "autonomy to enrich themselves at the cost of the" management (Eisenhardt, 1989: p. 62), will not be the case. Users will instead lean upon the management's choice of IS, and use their autonomy to comply with management's goal. Thus, the degree of user competence will not explain as much of perceived usefulness when goal harmony is high, as it will when goal harmony is low. Perceived competence was previously defined as the users' potential to fully utilize information and communication technology in order to improve his or her performance of specific job tasks (Lam \& Lee, 2006) and refers to the desire to feel effective in attaining valued outcomes. In situations with high level of goal harmony, the users desire to feel effective in attaining valued outcomes will be positively affected because the user will act in the best interests of management. Thus, in regarding the IS system as useful, the user is supposed to feel effective because the valued outcome, i.e. the usefulness of the system, is associated with obtaining common goals. Thus, it follows that a goal harmony relationship decreases the effect of perceived competence on perceived usefulness. Consequently, the more the harmonized the goals between management and users, the lesser the effect of perceived competence on perceived usefulness.

Perceived competence as (quasi) moderator. If there is low goal harmony in university management-user relationships, the user may act opportunistically, since the management cannot fully monitor the teacher's behavior and enforce compliance (Eisenhardt, 1989), and we would expect, ceteris paribus, a negative effect on perceived usefulness. If the users perceive their competence as high, however, it would be in the users' own interests to facilitate the best possible learning situation for themselves and their students. If the user has high competence and there is low goal harmony, she might behave opportunistically in several contexts and situations, but not to the same degree regarding the IS which she can utilize for her own personal advantage. Thus, teachers having obtained a certain level of competence will evaluate the systems as useful (Fleming, Motamedi, \& May, 2007) and to a lesser degree act opportunistically in this context, since integrating the technology in their future teaching would be in their own self-interest. Thus, perceived competence decreases the effect of goal harmony on perceived usefulness. Consequently, the higher the perceived competence, the lesser the effect of goal harmony on perceived usefulness.

The quasi moderators' interaction effect on perceived usefulness. As argued, perceived competence and goal harmony will to a certain degree be substitutes. The higher the perceived competence, the lower the effect of goal harmony on perceived usefulness; and, the stronger the goal harmony between management and users, the lower the effect of perceived competence on perceived usefulness. Thus, the concepts of goal harmony and perceived competence will have a negative interaction effect on perceived usefulness. We propose the following hypothesis:

H3: Perceived level of competence and goal harmony has a negative interaction effect on perceived usefulness.

\subsection{Controls}

While TAM predicts that the main antecedent of perceived usefulness is perceived ease of use (Davis, 1989), ISCT predicts that the antecedent of perceived usefulness is confirmation of the pre-accepted expectations (Bhattacherjee, 2001). Thus, perceived ease of use and confirmation are included as control variables.

Perceived ease of use. Perceived ease of use is defined by Davis (1989) as the "degree to which a person believes that using a particular system would be free of effort". Effort is a finite resource which a person may allocate to the various activities for which he or she is responsible (Radner \& Rotschild, 1975). Consequently, teachers' perceived usefulness of e-learning technology will be positively affected if the technology is perceived as easy to use. TAM has been supported through numerous studies (Shaikh \& Karjaluoto, 2015; Hong, Thong, \& Tam, 2006). Following TAM, we propose:

H4: Teachers' perceived level of ease of use has a positive effect on their level of perceived usefulness.

Confirmation. Users' confirmation of initial expectations is considered as an important precursor of perceived usefulness beliefs (Bhattacherjee, 2001), and represents the degree to which the systems meet the users' expectations. If the expectations are confirmed, perceived usefulness will be established accordingly. Thus, if the teachers' experience that their expectations related to e-learning technology is confirmed, a positive relationship between confirmation and perceived usefulness is expected. The following hypothesis is proposed: 
H5: Teachers' perceived level of confirmation has a positive effect on their level of perceived usefulness.

\section{Methods}

This study comprised an online survey distributed to teachers employed at a university college. The university college has approximately 6,500 students and approximately 460 teachers and is organized into four faculties and fourteen institutes. A dean manages each faculty, and the deans are included in the university college's management team. For several years, technology-enhanced and blended learning has been given high priority among the university management and teachers in specific institutes. However, the use of e-learning technology is regarded as voluntarily and there is considerable variance in the level of competence among the teachers and the actual use.

The survey participants comprise 177 teachers, which constitutes $38.5 \%$ of the teaching staff. More demographic information is presented in Table 1.

\section{Measurement}

All constructs except for goal harmony are measured using established items. Goal harmony is measured using a scale adapted from Bøe et al. (2015). The scale is based on the theoretical definition of the construct and the items are related to the goals communicated by the management. The purpose of the scale is to verify to what degree the faculties and the university management share the same goals related to the use of e-learning technology. Several interviews with experts in the setting were conducted to establish content validity for the constructs. All items are measured using a seven-point Likert-type scale (Table 2).

\section{Data Analysis}

Partial least squares (PLS) were employed as our analysis approach using the tool Smart PLS (Ringle, Wende, \& Will, 2005). By combining confirmatory factor analysis with linear regression, the measurement model and the structural model can be run simultaneously. The results are presented below.

\subsection{Assessment of the Measurement Model}

The assessment is performed according to the following criteria: 1) indicator reliability; 2) the convergent validities of measures associated with individual variables; and 3) discriminant validity between variables and items (Hulland, 1999). The mean, standard deviation, the factor loading, t-stat, composite reliability (CR) and average variance extracted (AVE) for each indicator are presented in Table 3 . The loading for all indicators are above the threshold of 0.7, expect for PerC3 with a value of 0.63 . However, this item is kept to obtain a broader

\begin{tabular}{cccc} 
Table 1. Demographic information. & & \\
\hline \multirow{2}{*}{ Gender } & Female & Frequency & Percentage \\
& Male & 87 & 49 \\
\multirow{2}{*}{ Age } & $<31$ & 90 & 51 \\
& $31-40$ & 5 & 2.8 \\
& $41-50$ & 30 & 16.9 \\
& $51-60$ & 52 & 29.4 \\
\multirow{3}{*}{ Position } & $>60$ & 64 & 36.2 \\
& Professor & 26 & 14.7 \\
& Associate Professor & 50 & 11.3 \\
& Assistant Professor & 88 & 25.4 \\
& College Lecturer & 4 & 49.7 \\
& Other & 20 & 2.3 \\
\end{tabular}


Table 2. Constructs and items.

Construct/Items

ISCT-Perceived usefulness (Bhattacherjee, 2001)

\begin{tabular}{|c|c|}
\hline PerU1 & Use of e-learning technology improves the quality of my education \\
\hline PerU2 & Use of e-learning technology increases my productivity as a teacher \\
\hline $\begin{array}{l}\text { PerU3 } \\
\text { PerU4 }\end{array}$ & $\begin{array}{l}\text { Use of e-learning technology enhances my effectiveness in my educational work } \\
\text { Overall, use of e-learning technology is useful in my educational work }\end{array}$ \\
\hline PerU4 & TAM—Perceived ease of use (Davis, 1989) \\
\hline PerEoU1 & Using e-learning technology in my teaching is easy \\
\hline \multirow[t]{2}{*}{ PerEoU2 } & I do find e-learning technology easy to use \\
\hline & ISCT-Confirmation (Bhattacherjee, 2001) \\
\hline Con1 & My experience with using e-learning technology is better than expected \\
\hline Con2 & E-learning technology is more supportive in my teaching than expected \\
\hline \multirow[t]{2}{*}{ Con3 } & Overall, most of my expectations from using e-learning technology were confirmed \\
\hline & SDT-Perceived competence (Sørebø, Halvari, Gulli, \& Kristiansen, 2009) \\
\hline PerC1 & My colleagues tell me I am good at using e-learning technology \\
\hline PerC2 & I have been able to learn interesting new skills related to e-learning technology \\
\hline \multirow[t]{2}{*}{ PerC3 } & I do feel I competent when using e-learning technology \\
\hline & PAT-Goal harmony_adapted (Bøe, Gulbrandsen, \& Sørebø, 2015) \\
\hline GoaH1 & E-learning technology will improve flexibility for the students \\
\hline GoaH2 & E-learning technology will improve the quality of teaching \\
\hline GoaH3 & E-learning technology will increase student throughput \\
\hline GoaH4 & E-learning technology will increase student recruitment \\
\hline
\end{tabular}

Table 3. Measurement model.

\begin{tabular}{|c|c|c|c|c|c|c|c|}
\hline Construct & Item & Mean & Std.dev. & Loading & T-stat & CR & AVE \\
\hline \multirow{4}{*}{$\begin{array}{l}\text { Perceived } \\
\text { usefulness }\end{array}$} & PerU1 & 5.02 & 1.55 & 0.89 & 42.41 & \multirow{4}{*}{0.94} & \multirow{4}{*}{0.79} \\
\hline & PerU2 & 4.69 & 1.66 & 0.92 & 67.05 & & \\
\hline & PerU3 & 4.80 & 1.67 & 0.87 & 30.03 & & \\
\hline & PerU4 & 5.38 & 1.55 & 0.88 & 41.54 & & \\
\hline \multirow{2}{*}{$\begin{array}{l}\text { Perceived } \\
\text { ease of use }\end{array}$} & PerEoU1 & 4.73 & 1.46 & 0.91 & 38.10 & \multirow{2}{*}{0.92} & \multirow{2}{*}{0.84} \\
\hline & PerEoU2 & 4.48 & 1.31 & 0.93 & 62.39 & & \\
\hline \multirow{3}{*}{ Confirmation } & Con1 & 4.44 & 1.15 & 0.83 & 14.79 & \multirow{3}{*}{0.88} & \multirow{3}{*}{0.71} \\
\hline & Con2 & 4.18 & 1.26 & 0.87 & 22.40 & & \\
\hline & Con3 & 4.67 & 1.26 & 0.83 & 22.49 & & \\
\hline \multirow{3}{*}{$\begin{array}{c}\text { Perceived } \\
\text { competence }\end{array}$} & PerC1 & 4.20 & 1.75 & 0.86 & 29.12 & \multirow{3}{*}{0.83} & \multirow{3}{*}{0.62} \\
\hline & PerC2 & 5.11 & 1.52 & 0.85 & 33.79 & & \\
\hline & PerC3 & 3.54 & 1.81 & 0.63 & 7.70 & & \\
\hline \multirow{4}{*}{ Goal harmony } & GoaH1 & 5.26 & 1.59 & 0.80 & 23.16 & \multirow{4}{*}{0.90} & \multirow{4}{*}{0.68} \\
\hline & GoaH2 & 4.15 & 1.67 & 0.88 & 67.82 & & \\
\hline & GoaH3 & 3.78 & 1.53 & 0.85 & 28.20 & & \\
\hline & GoaH4 & 4.27 & 1.55 & 0.77 & 17.18 & & \\
\hline
\end{tabular}


domain of the construct (Hulland, 1999). Finally, CR and AVE for each construct are presented. The values are all above the recommended levels of 0.7 and 0.5 respectively.

Discriminant validity is presented in Table 4. Employing the procedure recommended by Fornell \& Larcker (1981), we examine the correlation between the variables and the square root of the respective average variances extracted. The result is satisfactory, as the square root of average variance extracted value for the variables is greater that the off-diagonal correlations.

\subsection{Assessment of Structural Model}

The results of the structural model are presented in Figure 2. The explained variance $\left(\mathrm{R}^{2}\right)$ of perceived usefulness is shown in conjunction with the endogenous variable and the path coefficients are shown close to each path.

The assessment of the structural model shows that four out of five hypotheses are supported. We found no support for $\mathrm{H} 4$ which indicated a positive relationship between perceived ease of use and perceived usefulness. We found support for the hypothesized relationship between confirmation and perceived usefulness, H5 ( $\beta=$ $0.21 ; p<0.01$ ). Furthermore, H1 and H2 are supported with strong path coefficients, both with a $\beta=0.38 ; p<$ 0.001. Finally, the interaction effect of perceived competence and goal harmony on perceived usefulness, H3, is supported $(\beta=-0.12, p<0.01)$. The R-square value of perceived usefulness, representing the amount of variance explained by the independent variable, is $60 \%$.

\section{Discussion}

\subsection{Implication for Research}

The primary objective of this paper is to review and test dominant predictors of perceived usefulness. Our review shows that no previous studies have combined the core antecedents of perceived ease of use and confirmation

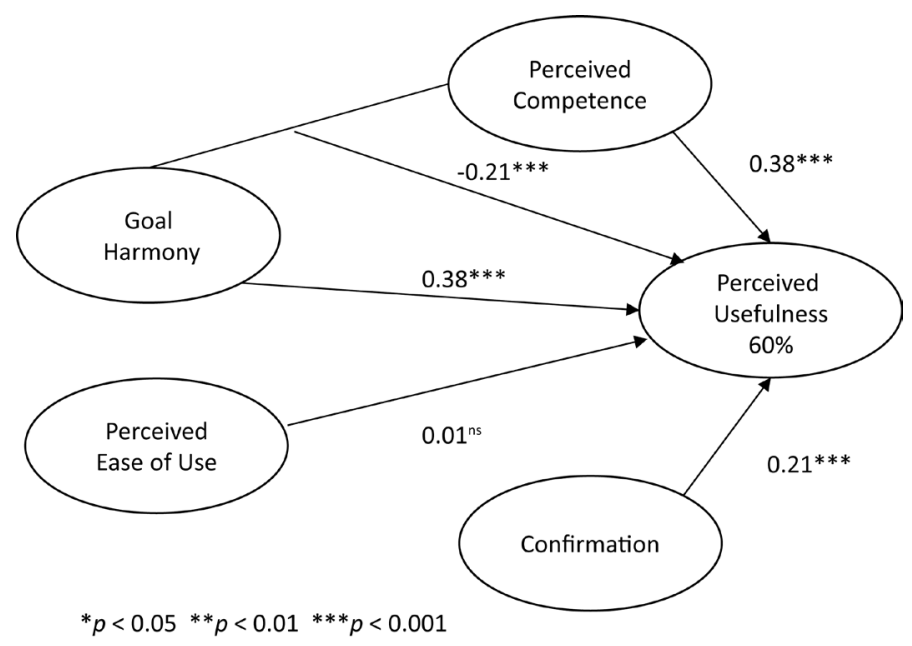

Figure 2. SEM analysis of the structural model.

Table 4. Discriminant validity.

\begin{tabular}{|c|c|c|c|c|c|}
\hline & Confirmation & Goal harmony & $\begin{array}{c}\text { Perceived } \\
\text { competence }\end{array}$ & $\begin{array}{l}\text { Perceived } \\
\text { usefulness }\end{array}$ & $\begin{array}{l}\text { Perceived ease } \\
\text { of use }\end{array}$ \\
\hline Confirmation & 0.84 & & & & \\
\hline Goal harmony & 0.44 & 0.83 & & & \\
\hline Perceived comp. & 0.38 & 0.36 & 0.79 & & \\
\hline Perceived usefulness & 0.54 & 0.61 & 0.61 & 0.89 & \\
\hline Perceived ease of use & 0.55 & 0.33 & 0.61 & 0.48 & 0.92 \\
\hline
\end{tabular}


with the antecedents of perceived competence and goal harmony when explaining perceived usefulness in an educational university setting. Overall, all the hypotheses were supported except for the relationship between perceived ease of use and perceived usefulness, and the R-square value of perceived usefulness, representing the amount of variance explained by the independent variables, is $60 \%$.

The study clarifies and integrates additional mechanisms and paths that are presumed to influence perceived usefulness more than previous studies have identified. Thus, perceived competence and goal harmony, derived from SDT and PAT respectively, were added to our research model. We believe that the paper makes three main contributions to the literature. First, we found strong support for the theoretical arguments of H1, that teachers' perceived competence has an positive impact on perceived usefulness $(\beta=0.38 ; p<0.001)$. Second, H2, stating that perceived degree of goal harmony with management influences the dependent variable $(\beta=0.38 ; p<0.001)$ was supported. In fact, both the latter antecedents exceeded confirmation as the most influential predictors of perceived usefulness. Third, the interaction effect of perceived competence and goal harmony on perceived usefulness, $\mathrm{H} 3$, is also supported $(\beta=-0.12, p<0.01)$. The latter interaction effect shows that the degree of user competence will not explain as much of perceived usefulness when goal harmony is high, as it will when goal harmony is low. However, since perceived competence and goal harmony is argued to be quasi moderators, the interaction effect also indicates that perceived competence decreases the effect of goal harmony on perceived usefulness, since it would be in the teacher's own interest not to act opportunistically in such situations. Consequently, integrating these three new paths represents a theoretical as well as an empirical contribution to the literature.

\subsection{Implication for Practice}

We believe our study addresses several issues of importance for management in educational institutions. First, we would emphasize the strong support for the relationship between goal harmony and perceived usefulness, indicating that the management of institutions must work hard to first establish clear goals and then make sure that these are adopted throughout the organization. Introduction of e-learning technology can help facilitate fulfilment of the strategic initiatives set forth by management. However, as in any other organization, implementation of new digital tools in higher education will be resource-intensive. Nevertheless, a situation of goal harmony will indicate that the university management and the faculty share the same goals, and will facilitate successful implementation and increase the level of perceived usefulness.

A second finding is the strong supported relationship between perceived competence and perceived usefulness. A major concern for the university management will be the adequacy and competence of its staff. Without this competence, the teacher may not able to see the perceived usefulness of the system and understand how this can be exploited to obtain the best possible learning situation for the students. Consequently, faculty development programs should be deployed to safeguard perceived usefulness of e-learning technology.

Finally, given the interaction effect of perceived competence and goal harmony, an IS-strategic analysis should be performed by the management in order to clarify the "as-is" situation of the institution. If the level of perceived competence is low, the management must put extra effort into securing goal harmony between the university management and the faculty, and vice versa; if the level of goal harmony is low, the management must put extra effort into increasing the competence of its staff.

\subsection{Limitations and Future Research}

There are several limitations in our study. First, there may be additional determinants influencing perceived usefulness beyond those tested in our study. For example, we do not include the constructs of perceived autonomy and perceive relatedness from SDT in our model, mainly because these factors are not empirically supported in previous studies (Sørebø, Halvari, Gulli, \& Kristiansen, 2009). There may also be theoretical arguments for including additional PAT-derived constructs. For example, risk-averse teachers may perceive the usefulness of a system differently than risk seekers. Future research should evaluate the relevance of adding antecedents other than the ones addressed in this study. Second, since our study is conducted in an educational university setting with teachers as the unit of analysis, our findings cannot necessarily be generalized to other settings. Additional research is needed to evaluate the generalizability of our findings. Third, the relationship between perceived ease of use and perceived usefulness, is not supported $(\beta=0.001)$. This may be explained by the demographic characteristics of the respondent group. For several years, this university college has been fo- 
cusing on technology-enhanced and blended learning. In such settings, these findings are in accordance with those from other studies (Bhattacherjee, 2001; Karahanna, Straub, \& Chervany, 1999), as "the effect of perceived ease of use tend to 'wear out' over time” (Bhattacherjee \& Lin, 2014: p. 3). Fourth, correlation design as used in this study has limitations when testing causal models. Thus, future research should employ longitudinal studies to establish causality.

\section{References}

Bhattacherjee, A. (1998). Managerial Influences on Intraorganizational Information Technology Use: A Principal-Agent Model. Decision Sciences, 29, 139-161. http://dx.doi.org/10.1111/j.1540-5915.1998.tb01347.x

Bhattacherjee, A. (2001). Understanding Information Systems Continuance: An Expectation-Confirmation Model. MIS Quarterly, 25, 351-370. http://dx.doi.org/10.2307/3250921

Bhattacherjee, A., \& Lin, C.-P. (2014). A Unified Model of IT Continuance: Three Complementary Perspectives and Crossover Effects. European Journal of Information Systems, Vol., 1-10.

Bøe, T., Gulbrandsen, B., \& Sørebø, Ø. (2015). How to Stimulate the Continued Use of ICT in Higher Education: Integrating Information Systems Continuance Theory and Agency Theory. Computers in Human Behavior, 50, 375-384.

http://dx.doi.org/10.1016/j.chb.2015.03.084

Davis, F. (1989). Perceived Usefulness, Perceived Ease of Use and User Acceptance of Information Technology. MIS Quarterly, 13, 319-340. http://dx.doi.org/10.2307/249008

Eisenhardt, K. (1989). Agency Theory: An Assessment and Review. Academy of Management Review, 14, 57-74.

Fleming, L., Motamedi, V., \& May, L. (2007). Predicting Preservice Teacher Competence in Computer Technology: Modeling and Application in Training Environments. Journal of Technology and Teacher Education, 15, 207-231.

Fornell, C. D., \& Lacker, D. F. (1981). Evaluating Structural Equation models with Unobservable Variables and Measurement Error. Journal of Marketing Research, 18, 39-50. http://dx.doi.org/10.2307/3151312

Hong, S.-J., Thong, J., \& Tam, K. (2006). Understanding Continued Information Technology Usage Behavior: A Comparison of Three Models in the Context of Mobile Internet. Decision Support Systems, 42, 1819-1834. http://dx.doi.org/10.1016/j.dss.2006.03.009

Hulland, J. (1999). Use of Partial Least Squares (PLS) in Strategic Management Research: A Review of Four Recent Studies. Strategic Management Journal, 20, 195-204. http://dx.doi.org/10.1002/(SICI)1097-0266(199902)20:2<195::AID-SMJ13>3.0.CO;2-7

Hung, M., Chang, I., \& Hwang, H. (2011). Exploring Academic Teachers Continuance toward the Web-Based Learning System: The Role of Causal Attributes. Computers \& Education, 57., 1530-1543. http://dx.doi.org/10.1016/j.compedu.2011.02.001

Islam, N. A. (2011). Extending Information System Continuance Theory with System Quality in E-Learning Context. AMCIS Proceedings, Detroit, 4-7 August 2011, 1-10.

Islam, N. A. (2012a). The Role of Perceived System Quality as Educators’ Motivation to Continue E-Learning System Use. Transactions on Human-Computer Interaction, 4:1., 25-43.

Islam, N. A. (2012b). Understanding E-Learning System Usage Outcomes in Hybrid Courses. 45th Hawaii International Conference on System Science (HICSS), Maui, 4-7 January 2012, 118-127.

http://dx.doi.org/10.1109/hicss.2012.613

Karahanna, E., Straub, D., \& Chervany, N. (1999). Information Technology Acceptance across Time: A Cross-Sectional Comparison of Pre-Adoption and Post-Adoption Beliefs. MIS Quarterly, 23, 183-213. http://dx.doi.org/10.2307/249751

Lam, J. C., \& Lee, M. K. (2006). Digital Inclusiveness—Longitudinal Study of Internet Adoption by Older Adults. Journal of Management Information Systems, 22, 177-206. http://dx.doi.org/10.2753/MIS0742-1222220407

Laugesen, J. (2012). The Role of Confirmation in IS Continuance Theory: A Comprehensive Meta-Analysis. International Conference on Information Systems 2012, 1-20.

Perrow, C. (1986). Economic Theories of Organization. Theory and Society, 15, 11-45. http://dx.doi.org/10.1007/BF00156926

Radner, R., \& Rotschild, M. (1975). On the Allocation of Effort. Journal of Economic Theory, 10, 358-376. http://dx.doi.org/10.1016/0022-0531(75)90006-X

Ringle, C. M., Wende, S., \& Will, A. (2005). Smart PLS 2.0 M3. Hamburg: University of Hamburg. www.smartpls.de

Roca, J. C., \& Gagné, M. (2008). Understanding E-Learning Continuance Intention in the Workplace: A Self-Determination Theory Perspective. Computers in Human Behavior, 24, 1585-1604. http://dx.doi.org/10.1016/j.chb.2007.06.001 
Shaikh, A. A., \& Karjaluoto, H. (2015). Making the Most of Information Technology \& System Usage: A Literature Review, Framework and Future Research Agenda. Computers in Human Behavior, 49, 541-566. http://dx.doi.org/10.1016/j.chb.2015.03.059

Sharma, S., Durand, R. M., \& Gur-Arie, O. (1981). Identification and Analysis of Moderator Variables. Journal of marketing Research, 18, 291-300. http://dx.doi.org/10.2307/3150970

Sørebø, Ø., Halvari, H., Gulli, V. F., \& Kristiansen, R. (2009). The Role of Self-Determination Theory in Explaining Teachers’ Motivation to Continue to Use E-Learning Technology. Computers \& Education, 53, 1177-1187. http://dx.doi.org/10.1016/j.compedu.2009.06.001

Tao, Y.-H., Cheng, C.-J., \& Sun, S.-Y. (2012). Alignment of Teacher and Student Perceptions on the Continued Use of Business Simulation Games. Educational Technology \& Society, 15, 177-189.

Teo, T., Lee, C. B., Chai, C. S., \& Choy, D. (2009). Modelling Pre-Service Teachers' Perceived Usefulness of an ICT-Based of an ICT-Based Student-Centred Learning (SCL) Curriculum: A Singapore Study. Asia Pacific Education Review, 10, 535-545. http://dx.doi.org/10.1007/s12564-009-9051-y

Wright, P., Mukherji, A., \& Kroll, M. J. (2001). A Reexamination of Agency Theory Assumptions: Extensions and Extrapolations. The Journal of Socio-Economics, 30, 413-429. http://dx.doi.org/10.1016/S1053-5357(01)00102-0

Ørnes, H. (2015). Digital tilstand 2014-Norgesuniversitetets monitor. Tromsø: Norgesuniversitetet. 